\title{
A VILA DESERDADA E A RE-TERRITORIALIZAÇÃO DOS SENTIDOS NA TEMPORALIDADE CONSTRUÍDA (LA GRAND-COMBE, FRANÇA)
}

\section{Cornelia Eckert}

No quadro industrial do século XIX na França, o carvão aparecia como fonte econômica básica. Entidades foram criadas para explorar o "ouro negro", trabalhadores foram requisitados para extraí-lo, vilas foram organizadas para mediatizar a relação entre os homens e o trabalho produtivo. O "universo da mina" foi cartografado como um espaço específico, onde o trabalho era paradigma dominante na história singular de coletividades. Em torno do trabalho na mina, famílias foram enraizadas e comunidades de trabalho, fundadas. Em relação ao "mundo da mina", combinaram suas aspirações, conceberam suas chances objetivas de um projeto de vida, construíram suas culturas.

$\mathrm{Na}$ atualidade, a maioria destas vilas conhece uma situação regressiva do mundo da mina e confronta-se com dificuldades econômicas. O fim das minas de carvão transtorna e desordena culturas singulares que gravitavam em torno da extração carbonífera. São os imperativos da civilização industrial e capitalista que transparecem na situação "de crise" no meio mineiro francês: o carvão, fonte energética $n^{\circ} 1$ durante mais de um século, não ocupa mais o podium, o petróleo o suplantou. Para seguir o caminho do progresso, o setor carbonífero sofreu uma profunda modernização em seu sistema de exploração. A isto seguiram-se o desaparecimento do trabalho na mina, o fim da tradicional atividade de mineiro "de pai para filho", a transformação de toda uma organização econômica e social destas comunidades ocupacionais. A fim de perseguir um itinerário ativo, homens e mulheres viramse obrigados a buscar novos horizontes de trabalho, e foram sobretudo aposentados e desempregados os que permaneceram nas vilas marcadas pela crise.

A oportunidade de desenvolver um programa de doutorado na França (1986-1991) veio ao encontro do meu interesse em refletir sobre as transformações sobrevindas no modo de vida de famílias de mineiros frente a recessão carbonífera. Para analisar este contexto, optei por um estudo de caso. A escolha foi La Grand-Combe, situada no sudeste da França, a 
$192 \mathrm{~km}$ do Mediterrâneo e a 650km de Paris, no Departamento do Gard (Languedoc-Midi). ${ }^{(1)}$

No seio de uma região agrícola e protestante ${ }^{(2)}$, nasceu uma microcivilização mineira e católica. La Grand-Combe nasceu da vontade de uma Companhia de Minas que aspirava desenvolver a indústria do carvão e dinamizar uma aglomeração urbana em torno desta unidade extrativa, a submetendo a um enquadramento paternalista, o que implicou a obtenção de um consenso em torno de seu projeto de construção de uma comunidade de trabalho( ${ }^{(3)}$ como uma "família corporativa". A Companhia cercou-se de uma vila colocada a seu serviço, uma vila política nos termos de François Ewald ${ }^{(4)}$. Foi esta Companhia que estabeleceu o plano diretor de urbanização e construiu a infra-estrutura necessária (escolas, hospital, centros administrativos, igreja etc) nesta vila que já nasceu com um compromisso, "um casamento de razão, ela teve que esposar um grande Senhor da Terra: o carvão".(5) O "país mineiro"(6) de

Cévennes alicerçou, por mais de um século a trajetória de uma comunidade de mineiros.

Hoje, após ter vivido um longo período regido por um sistema mono-industrial e de urbanização do tipo vila-mineira, a cidade sofre um processo de desindustrialização pelo recesso de sua atividade econômica dominante. Depois de registrar uma população de 20.000 habitantes, os 7 mil habitantes atuais deixam transparecer o drama vivido.

\footnotetext{
1. Foi com a leitura de uma citação feita por Rolande Trempé, na sua obra sobre os mineiros de Carmaux que minha atenção recaiu sobre esta vila. Ver TREMPE. (1971).

2. Cévennes sempre foi bastião protestante e republicano. Em 1704, os Camisards são vencidos pelas forças royalistas, mas no século XVIII, um regime de tolerância se instala. A comunidade protestante cevenol é, desde então, fiel ao regime republicano e durante todo o século XIX serão considerados os "radicais e socialistas" em oposição aos católicos que defendem em massa o partido royalista. Os diversos episódios revolucionários são confundidos com estes conflitos seculares, mesmo no século XX: os protestantes serão liberais votando à esquerda, os católicos serão conservadores e votam à direita. Cf. JOUTARD, PH. "Les Cévennes, bastion républicain et Vendée méridionale". In: JOUTARD. (1979). pp. 143 a 153.

3. Identifico este grupo operário como uma comunidade de trabalho porque esta conceituação ajuda a compreender a maneira própria de os personagens em questão cartografarem o seu mundo de pertencimento social e de recortar as fronteiras culturais em relação ao mundo mineiro. Comunidade de trabalho é uma outra maneira de dizer grupo de identidade, de destino, ou de fazer uma homologia entre a grande família mineira e as relações marcadas por uma trajetória, uma condição de vida em comum, assim como são comuns valores como a solidariedade, a reciprocidade, a cumplicidade. Uma comunidade igualmente recortada por outras unidades de identidade fundamentais como família, religião, bairro, vizinhança, sindicato, partidos políticos etc, que são ora complementares, ora dilacerantes das fronteiras imaginadas como constitutivas da comunidade de trabalho. O processo de reatualização destas fronteiras é uma manipulação incessante das diversas referências sócio-culturais inscritas sobre as propriedades de situações variáveis. Esta tensão coloca em destaque a dinâmica histórico- social. Na maneira de cartografarem seu mundo de pertencimento com significação, os entrevistados acionam as referências culturais que os transportam a estes micromundos de pertencimento e que os fazem deslizar num feixe de valores em relação aos universos complementares individualista/hierárquico (holista) que se distinguem segundo a situação à qual o valor é suposto.

4. Vila e usina são organizadas segundo os princípios de uma mesma economia, sob a direção de um "patrão" como "sociedade". EWALD. (1986).

5. LIVET. (1956). p. 23.

6. "Le pays minier", dizem os nativos, "tombée", en occitan. O país, neste contexto, é o espaço onde os habitantes participam de um mesmo meio econômico e vida social.
} 
Nesta pesquisa colocam-se em alto relevo a vida e o trabalho dos mineiros grandcombianos e de suas famílias não somente em relação à sua inserção no mundo plural, do mercado moderno (com o qual eles estão confrontados), mas também a outras totalizações que colocam em destaque suas configurações de valores. Dimensiona-se sua maneira singular de viver e de pensar, o que é percebido na representação e na prática social intrinsecamente articuladas. Isto significa dizer que o sistema social é visto como um sistema de significações e a cultura como dimensão de um sistema de representações e de práticas sociais no qual se estabelecem as distinções e identificações na constituição de um senso de mundo.

\section{Um estudo de Antropologia social}

Este estudo de caso foi construído a partir de um trabalho de campo em La GrandCombe desenvolvido durante 9 meses, entre 1987 e 1990, tendo por objetivos: a) conhecer a situação vivida pelos mineiros de carvão grand-combianos frente ao desaparecimento do seu mundo de referência (a mina) e de sua profissão (mineiro), o que provocou a dispersão da comunidade tradicionalmente ligada a esta prática de trabalho; b) entender como este grupo operário se reorganiza face à situação de "desordem" da identidade social da comunidade de trabalho; conhecer o impacto sofrido pelos habitantes nos diferentes domínios da vida social, as transformações no seu modo de vida e sua cultura; c) analisar, enfim, como as famílias ali ainda residentes, herdeiras de um tempo coletivo e portadoras da memória do grupo, repensam seu tempo vivido através do olhar pousado sobre o passado, reordenando o tempo presente.

Minha motivação antropológica consiste, por um lado em estudar o processo de construção da identidade social $^{(7)}$ de um grupo face a uma experiência de trabalho percebida como diferencial e singular. Os mineiros de carvão grand-combianos viveram durante mais de um século, o tempo coletivo da comunidade de trabalho, dividindo a experiência particular de inserção no mundo da mina e na vida da vila mineira. Seja na observação de campo, seja na representação dos entrevistados, o "seu" mundo é cartografado como específico, pelo modo de vida singular e pela condição de vida operária no interior de contextos históricos e sociológicos constitutivos de um "coletivo": um "mundo mineiro", a partir do qual eles 
qualificam referências e valores de sua cultura no processo de construção da identidade social.

Por outro lado, busco conhecer a construção da trajetória da comunidade de trabalho na sua maneira própria de pensar a continuidade sobre as descontinuidades de sua história coletiva, na sua maneira de pensar a ordenação de superposições temporais vividas. É na reflexão sobre a construção da identidade social que se reconhece o ritmo do cotidiano deste grupo de pertencimento na dinamização da sua memória sobre um passado e um presente que exprimem uma relação temporal vivida numa "ondulação dialética"(8). Pela dinamização da memória do grupo, os sujeitos consolidam uma temporalidade vivida como coletiva, rica em significações. ${ }^{(9)}$

Estes ritmos vividos pensados ("rythmanálise"(10)), são múltiplos, entrecortados por outros tempos plurais, mas passíveis de um ordenamento temporal ancorado no "mundo da mina" como constitutivo de uma comunidade de identidade fundada sobre o valor-trabalho. $\mathrm{O}$ passado, então, não é necessariamente antagônico ao presente. "Nosso passado inteiro também vela atrás de nosso presente"(11), os tempos vividos são pensados como superpostos como um movimento dialético de continuidades e descontinuidades da duração social. Assim, para comprender o presente do grupo estudado, é preciso conceber o tempo social como um série de rupturas, evitando perceber sua história num eixo temporal contínuo e uniforme. Esta posição motiva a trabalhar com a memória coletiva e social $^{(12)}$, já que a memória não obedece a uma ordem cronológica, corresponde antes a maneiras de ativar uma ordem com significado dos traços mnésicos.

Fica claro porque é a população mais idosa, os aposentados da mina, que compõe o grupo numericamente privilegiado em minhas entrevistas. Nas suas narrativas retraçam o

7 . Sobre conceito de identidade social sigo DIAS DUARTE.(1986) e LEVI-STRAUSS.(1983).

8. BACHELARD.(1988). p. 76.

9 . "... o tempo pensado é tempo vivido em estado nascente, ou seja, que o pensamento é sempre, em alguns aspectos, a tentativa ou o esboço de uma vida nova, uma tentativa de viver de outro modo, de viver mais ou até mesmo, como queria Simmel, uma vontade de ultrapassar a vida. Pensar o tempo é enquadrar, localizar a vida; não é tirar da vida uma aparência particular, que se captaria de modo tanto mais claro quanto mais se tiver vivido. É quase fatalmente propor que se viva de outro modo, que se retifique antes de tudo a vida e em seguida que se a enriqueça." In: BACHELARD. (1988). p. 76.

10 . "... A ritmanálise procura em toda parte ocasiões para ritmos. ... Ela nos previne assim sobre o perigo que há em viver no contratempo, desconhecendo a necessidade fundamental das dialéticas temporais". In: BACHELARD. (1988). p. 133.

11 . BACHELARD. (1988). p. 11.

12. Sobre memória coletiva e social recorrer a: a) HALBWACHS.(1968); NAMER.(1987); JEUDY. (1986);

BACHELARD.

(1988); BOSI. (1987) (etc, cf. bibliografia). 
passado, reordenando e reatualizando no tempo presente as referências identitárias. Nestas reordenações temporais, não importa quais sejam as representações em torno da família, do grupo, da vila, da sociedade, o trabalho na mina permanece sendo sempre referência. É o nascimento, a existência e o desaparecimento desta atividade que fornece o reconhecimento da história do grupo e da vila.

Viver hoje é igualmente guardar uma ligação ao passado, emprestando sentido aos valores e às práticas coletivas e individuais no presente. Mesmo sem referências espaciais reais, os grand-combianos pensam um tempo vivido reordenado a partir de ritmos jamais ausentes, porque se muito mudou, as pessoas estão ainda lá. Velhos e jovens ficaram, enraizados, e reapropriam-se de lugares sociais onde possam ordenar o tempo com novos ritmos de correspondências temporais: tempos pessoais, tempos do mundo.

\section{Era uma vez uma vila mineira...}

Privilegiando ora as práticas familiares, ora as relações de vizinhança, ora as formas e processos de sociabilidade, conheceram-se os autores que desempenham personagens diversos no teatro da vida cotidiana hoje.

Desde as primeiras entrevistas, os informantes narraram sua história local e sua trajetória de vida em diferentes intervalos temporais. Num processo de ordenamento da memória, reconstituíram o vivido no passado, quando a mina ainda existia e mais do que um meio de trabalho, era toda uma razão de existência e de composição de redes de relações. Viver o presente, ao contrário, foi exteriorizado como uma época marcada pelo fim do trabalho na mina.

As evocações do vivido ontem foram enunciadas pelas expressões "no tempo da Companhia" e "no tempo da mina". São, portanto, os tempos sociais de um passado ritmado pelo trabalho na mina e do nascimento da vila, que eles ordenam para encadear o passado em uma relação lógica com o tempo presente. É "no tempo da Companhia" que é criada a vila capaz de amalgamar trajetórias heterodoxas para fundar a população grand-combiana. É "no tempo da Companhia" que é localizada a origem da comunidade de trabalho, fundada como uma "grande família corporativa".

Batizada com o mesmo nome da Companhia, La Grand-Combe foi fundada como vila 
por uma lei promulgada em junho de 1846, estendendo-se sobre uma superfície de 6.000 hectares, no Gard. La Grand-Combe tornou-se o centro de diversos vilarejos periféricos dispersos. Desde sua criação, a vila e a Companhia conheceram uma dinâmica recíproca. A vila viveu à sombra da Companhia: a demografia positiva ou negativa exprimia as necessidades de mão-de-obra por parte da empresa e suas estratégias de recrutamento; a urbanização foi condicionada pelo interesse e necessidades estruturais desta mono-indústria, o poder local era exercido por representantes da Companhia que garantiam, assim, o interesse patronal e o domínio sobre a área urbana.

As vésperas da criação da vila de La Grand-Combe, reuniam-se nas circunvizinhanças cerca de 4.000 habitantes, contando, de imediato, com uma mão-de-obra local, composta na sua maioria por camponeses dos arredores. Habituada a um modo de vida inteiramente voltado ao trabalho agrícola, esta população apresentou um comportamento migratório e sazonal. O absenteísmo sistemático dos mineiros-camponeses, que costumavam voltar às suas terras em épocas de colheita, e sua lenta adaptação à extração em galerias profundas eram entraves aos interesses da Companhia, sobretudo frente a uma demanda de carvão superior à capacidade de produção. Era necessário recrutar e formar uma população operária mais estável e mais qualificada, medida indispensável para ganhar o mercado. A Companhia orientou então suas estratégias para o crescimento da mão-de-obra e a organização de um complexo urbano. Para isto, recrutou mineiros estrangeiros, vindos da Itália e da Bélgica, e profissionais de outras províncias francesas.

Mas, de fato o que sustentou estes movimentos migratórios? O que levou estas pessoas a deixarem seus países, regiões e atividades de origem? O que as ativou a ponto de aceitarem esta mobilidade, um novo modo de vida, uma nova mentalidade? Por que aceitaram compor uma mão-de-obra que respondia aos apelos de uma profissão tão dura?

A resposta é complexa, mas pode-se considerar como indícios os meios dinamizados pela Companhia para estimular o enraizamento em La Grand-Combe: o desenvolvimento de uma comunidade corporativa, a criação de uma vila baseada em um poder paternalista e uma atitude assistencial assegurada pelo patronato.

Antes mesmo de ver aprovados os processos destinados a negociar a criação de um novo território municipal, a Companhia desenvolveu uma política de habitação e ensino. No mesmo espírito, criou instituições sociais como a caixa de seguros, de aposentadoria e de poupança para seus trabalhadores, no que é uma das precursoras na época. A estratégia 
política e a iniciativa industrial apoiavam-se em primeiro lugar na construção de uma vila operária, e isto significava atribuição de alojamento. O dueto trabalho-teto é, sem dúvida, um instrumento de sedução eficaz para explicar o efeito criado no imaginário destes camponeses confrontados com as dificuldades do trabalho agrícola (epidemias, crises) ou destes operários confrontados com as duras condições de sobrevivência impostas pelo desenvolvimento industrial nos seus inícios. São conhecidos os constrangimentos sofridos por esta população operária no século XIX: fragilidade de ganhos, irregularidade de trabalho, promiscuidade, ausência de higiene, fome, má nutrição, enorme mortalidade infantil etc.

É necessário, ainda, adaptá-los a um novo modo de vida, estimulando a adequação a um $\operatorname{habitus}^{(13)}$, a uma sociabilidade operária. Esta política publicitária baseada em vantagens correspondia mais a uma tática de estabilização, de enraizamento, que a uma estratégia de imobilização dos operários. No conjunto da vida local de La Grand-Combe, "a Companhia" queria que o trabalho fosse o elemento dominante na cultura operária da "grande família corporativa". Para tanto, a Companhia desenvolveu uma política de "ordem moral"(14), que considerava o sistema de organização produtiva e social em harmonia com as relações sociais dominantes na vila. A questão era a construção de um cotidiano equilibrado fundado sobre a vida em família, instituição social considerada como base de estabilização dos trabalhadores e da coletividade.

O patronato da Companhia de Minas de La Grand-Combe orquestrava a organização da vida cotidiana, estruturando não somente o espaço e o tempo familiar, mas também as formas de reprodução da família operária. Face à necessidade de aumentar a mão-de-obra, é sobre os próprios recursos humanos locais que a Companhia queria contar. Seu objetivo era estimular a auto-reprodução da força-de-trabalho local empreendendo um plano de hereditariedade profissional, assegurando a reprodução endógena da população. A família nuclearizada (pai, mäe, filhos) foi idealizada, e as alocações encorajaram materialmente o desenvolvimento de

13. "Un système de dispositions durables et transposables qui, intégrant toutes les expériences passées, fonctionne à chaque moment comme une matrice de perceptions, d'appréciations et d'actions". BOURDIEU. (1972). p. 178.

14. "(...) ce qui nous préoccupe surtout, c'est l'amélioration du sort de l'ouvrier pour tout ce qui dépend de nous. C'est en effet en rendant attrayant pour lui la colonie de La Grand-Combe, c'est en lui assurant la vie à bon marché, l'éducation et l'emploi de ses enfants, l'assistance morale et matérielle, une administration équitable et paternelle que nous parviendrons à attirer et à conserver les bons ouvriers, c'est-à-dire les ouvriers laborieux, rangés, pères de famille". In: Rapport des gérants sur l'exercice

1846. Assemblée Générale du 28 mars 1847. 
famílias numerosas.

A Companhia foi bem sucedida no seu programa de estabilização de mão-de-obra, conforme os dados de taxa de aumento da natalidade. Considerando igualmente a imigração sistemática, a população grand-combiana cresceu em rápidas proporções (11.341 h. em 1886, 13.358 h. em 1896) ${ }^{(15)}$.

Dar conta do papel patronal no processo de construção do espaço urbano é enfocar também a dinâmica das relações sociais na vila. La Grand-Combe nasceu de um projeto urbano traçado pela Companhia. O plano urbano foi condicionado pelos interesses e necessidades estruturais da mono-indústria que estabeleceu uma relação lógica entre os espaços de trabalho, público e doméstico, e foi sobre esta base que a Companhia fundou estes espaços sobre o qual inscreveu sua estratégia industrial e cristalizou a imagem de "vilaoperária".

O domínio da Companhia sobre o conjunto dos níveis da vida social e a hegemonia patronal sobre a vida local desenharam um universo profissional fechado. Esta base foi sustentada por uma composição social pouco complexa, conseqüência de uma estrutura profissional concentrada de modo monolítico no setor carbonífero. A carreira era por consequiência "operária". Bem que existia uma certa dose de "consentimento do destino", seguir a mesma trajetória de pai para filho era antes de mais nada visto como o único "mundo do possível".

Outrossim, as famílias desta corporação pertencem a um universo cuja dinâmica é paradoxalmente ligada à morte, à doença, à fatalidade, experimentações que lhes informam sentimentos cotidianos expressos em suas representações sobre o viver no "tempo da Companhia". Os entrevistados insistem na palavra "solidariedade"(16) para falar das qualidades dominantes que outrora fundamentavam a vida coletiva. A solidariedade, a cumplicidade, disseram, "unia todos os mineiros". Sentimento que os totaliza na condição necessária de coesão, preenchendo uma função de ordenação do mundo social. Experiência fixada na especificidade da atividade da mina, por condições de trabalho estreitamente ligadas ao perigo e à insalubridade.

15. Com o passar dos anos a imigração diminui e o celibato masculino decresce embora a população não cesse de aumentar, os casamentos locais e o número de pessoas de $3^{\circ}$ idade aumentam, prova de que o período pioneiro de povoamento chega à seu termo, signo de maturidade da vila.

16. A solidariedade faz apelo antes à luta do que ao sentimento. Cf. DUVIGNAUD. (1986). p. 10. 
Se muito é dito sobre a passividade dos mineiros grand-combianos no "tempo da Companhia" (seu pessoal tem mesmo a reputação nacional de dóceis e resignados), deve ser dimensionada no âmago da vida cotidiana, a luta coletiva, as contestações invisíveis ou não da comunidade de trabalho que se opunham à corrente tutelar da Companhia. Nos anos que fecharam o século XIX, surgiram as primeiras tentativas de organização sindical e de greves. Nos anos que abrem o século XX, a organização operária não cessa de se consolidar. Isto significava que os mineiros experimentavam sua entrada definitiva no mundo operário organizado. A luta sindical passou a fazer parte da vida cotidiana desta comunidade.

Formas de cumplicidade foram desenvolvidas neste trabalho de alto risco, explicam eles, valores passados como próprios do savoir e faire da profissão. Visualiza-se na pesquisa formas de cumplicidade e de oposição diversas que informam mecanismos silenciosos de resistência ao consentimento servil. Aqui importa citar a importância do dialeto dos mineiros (patois minier) ${ }^{(17)}$ no cotidiano do trabalho e na expressão de uma "cultura mineira".

Durante 110 anos a toda poderosa Companhia reina absoluta sobre La Grand-Combe dirigindo-a segundo seus interesses, particularizando os hábitos da comunidade, transfigurando paisagens e monopolizando a economia. Mas a conjuntura da Segunda Guerra Mundial quebra abruptamente o tempo do jugo paternalista que se queria permanente. Os eventos históricos quebram a eficácia deste continuum ilusório. Os anos pós-guerra foram anos de estruturas que caíram, de modos de viver e pensar colocados em xeque, povos remobilizados, hierarquias, prestígios e valores afetados, enfim, foi toda uma "transformação estrutural global de caráter revolucionário"(18).

Esta descontinuidade no tempo coletivo é pensada pelos entrevistados de forma tão profunda, que eles tecem novas referências estruturais para ordenar "o tempo vivido". Os grand-combianos viveram este evento como de acentuadas transformações, em que a nacionalização das minas lhes significou sobremaneira. As minas da França foram nacionalizadas por decreto promulgado em 1946 e todo o complexo industrial da Companhia passou a pertencer às Hulherias da Bacia de Cévennes, grupo sudeste da Central Carbonífera

17. Mais sutil, mas não menos importante instrumento de contestação era a apropriação, por parte dos mineiros, da língua nativa cevenol. Com freqüência os informantes repetem sobre uma certa autonomia na organização do trabalho no fundo da mina e vêem aí o espaço que permitiu o desenvolvimento de um espírito de companheirismo, onde "apreende-se a profissão e conhece-se o que é a mina".

18. Cf. BALANDIER. (1983). p. 107. 
da França.

Com a promulgação da nacionalização, as mudanças de época foram patentes. Os grand-combianos referem-se ao vivido como o "tempo da nacionalização das minas". As transformações fizeram-se sentir em diferentes domínios (econômico, político, social). Novas disposições administrativas são instituídas inserindo os mineiros numa entidade econômica de razão social regional. Passaram a ser recenseados no conjunto dos efetivos das Hulherias de Cévennes, que contava com um total de 21.000 operários em 1947, com sedes em Alès (cidade vizinha) e em La Grand-Combe.

Mas para La Grand-Combe, as mudanças econômicas trazidas com a nacionalização das minas não faziam mais que confirmar a fragilidade de uma estrutura cimentada na monoatividade extrativa. Na virada da década de 60, a crise se instala no setor carbonífero. As promessas de reconversão industrial em Cévennes eram tema de primeira página nos jornais, enquanto poços de extração eram fechados um após o outro, prelúdio de um refluxo econômico irreversível que se instalava no setor.

Estranha época de progresso grávida do declínio do ouro negro, do fim da vila mineira, da explosão da comunidade de trabalho, da reconversão ou aposentadoria de toda uma população ativa, do desemprego dos jovens ou da sua busca forçada de novos campos de trabalho. Tudo isto foi causa de desencantamentos, desesperanças e exaltação de sentimentos xenófobos.

A mina tornou-se "o último lugar da indústria", o carvão, "um combate de retrocesso" ${ }^{(19)}$. Os mineiros, que haviam comprendido, ao longo destes anos de inserção neste meio, que cabia a eles conquistar melhores condições de vida e de trabalho, lutar pelo "desenvolvimento", viam agora que, ironicamente, nesta alegoria de "progresso", vinham as próprias contradições da modernidade: superação das indústrias tradicionais, desemprego, disputa num mercado de trabalho discriminatório, racista etc.

Sem a mina, foi a profissão que desapareceu e com ela valores de referência de um grupo, de uma prática social e um modo de vida. É claro que La Grand-Combe não foi um caso isolado; em toda França os antigos "reinos mineiros", após anos de glória e prosperidade, foram atingidos. Para todos eles, "a mina não foi somente um dado econômico", muito mais

\footnotetext{
19. Cito LUCAS. (1985). p. 146.
} 
que isto, "o que gostaríamos de chamar de um 'fato social total"'(20).

Nos anos 70, poços e torres de extração considerados dos mais modernos da Europa foram fechados e dinamitados. Ficou claro aos mineiros que nem mesmo a modernização do setor frearia o declínio. Nos anos 80 , todos os sinais da atividade mineira subterrânea foram desativados, era o ponto de não-retorno. A mina desapareceu e com ela os espaços de referência identitária. Modificou-se toda a trama cotidiana de existência, o tecido urbano foi deslocado, o corpo social desintegrado: "é o fim do mundo da mina", explicam os mineiros, é igualmente a desestruturação da comunidade de mineiros, porque "a profissão não existe mais", a não ser nas disformidades que secretaram a morte da mina: os mineiros aposentados, o patrimônio mineiro, a memória "do" social.

O tempo presente é considerado como tributário dos erros acumulados do passado e de uma conjuntura de crise que se inicia com o fechamento dos poços. Junto às mudanças econômico-industriais que despontam neste antigo reino do desenvolvimento do carvão, as rupturas são profundas: é o fim da atividade tradicional na mina, o fim da profissão de mineiro e da tradição da comunidade de trabalho, da hereditariedade do "ser mineiro". Esvaziada desta substância industrial que havia forjado a identidade dos habitantes, La Grand-Combe é destituída de seus status de vila mineira.

A força desta ruptura foi tão dramática que no discurso dos mineiros um outro tempo é pensado como superposto "aos tempos da mina". Estas famílias que durante gerações viveram uma estabilidade de trajetória com contornos firmes, reordenam agora suas projeções a partir de concepções de um mundo às avessas, da improbabilidade: "o tempo de crise", "o tempo da recessão". Na atualidade, este corte desmedido da continuidade da comunidade de trabalho porta um impacto e sofrimentos: é todo um conjunto de tradições próprias que desaparece nos "tempos letárgicos".

Hoje, embaraçados em suas próprias diferenças e pluralidades, os velhos habitantes exprimem a ruptura do tempo coletivo da comunidade de solidariedade e falam da dificuldade de reordenar nos novos tempos, os valores de referências da identidade. A tendência à forte privacidade, aliás, vem de uma opção por proteção de um mundo também estranho.

Entretanto, se a vida social se transforma, ela continua, ela não é somente ruptura.

20. SCHWARTZ. (1990). p. 11. 
Sobre esta, uma outra ordenação é pensada, exprimindo o ritmo dos esforços humanos em construir um devir que não será jamais oposição ou contradição ao passado e ao presente, mas superposição temporal num movimento ondulatório, no perpétuo recomeçar social.

A vida cotidiana dos aposentados da mina, dimensão fundamental para compreender o universo simbólico deste grupo, desenvolve-se hoje sobretudo com práticas informais, lúdicas, que traduzem maneiras de pensar e de exprimir suas condições de existência marcadas pela inatividade (de produção de capital); preenche-se um tempo livre excedente. Apesar da profunda hemorragia demográfica da vila, a coletividade quer ainda exprimir sua coesão. Rejeita o esquecimento global, vive a comunhão em formas plurais de interação, concretizando espaços sociais onde vivem laços afetivos e de reconhecimento. Constantemente, nos lugares de sociabilidade, nega-se a volatização do tempo, reencontramse as pessoas e reconstituem-se maneiras de ser coletivas.

Apesar do desaparecimento dos espaços reais sobre os quais o grupo fundou sua identidade, pela memória a comunidade de trabalho pode colar suas referências a certos momentos de interação vividos como sendo seu próprio ritmo construído. É analisando seus espaços de sociabilidade cotidiana (na feira pública semanal, nos jogos de bocha, nas atividades de clubes de terceira idade, nas festas populares, municipais, familiares, etc, tanto quanto nas formas de consumo dos meios de comunicação de massa) que demonstra-se a reconstituição de um ritmo ao cotidiano, um senso à existência do grupo, sua cultura, posto que "não existe nenhuma razão, natural ou não, para que uma sociedade se conserve, salvo justamente a sua cultura, que é o instrumento de luta contra a dissolução"(21).

Os "tempos de crise" não são vazios de significação. Apesar das rupturas, a comunidade vai se esforçando por se recolar. A memória coletiva aparece como uma referência essencial para a reatualização da identidade do grupo. É por ela que o tempo vivido é reordenado. Conscientemente ou não, os grand-combianos retomam um outro ritmo cotidiano, reatualizam sua vida familiar, recosturam redes sociais diversas.

O grupo reconstitui, pela memória, o tempo coletivo que se superpõe às rupturas: rememoram-se fatos e instantes recusando a morte global, engendra-se a continuidade, não sem a dimensão do sofrimento e da "tragédia". Graças à memória social, a comunidade de

21. DUVIGNAUD.(1983). 
trabalho reordena no presente as referências simbólicas do passado que continuam a guiá-la em direção a algum futuro.

Hoje, os grand-combiannos devem continuar a construir sua própria vida e a lutar para resolver seus problemas. Eles não podem, sem dúvida, chegar a este fim individualmente, mas a partir de redes comunitárias, da sociabilidade elaborada no dia-a-dia: a família, a vizinhança, a vida associativa etc, que implicam a tomada dos espaços de interação diversos, a casa, o bairro, os clubes, a vila, a região, o país...

Não se fala com otimismo do futuro, mas este é incessantemente construído, e se ele não é definido claramente, é desejado sem cessar, trabalhado nos interstícios das práticas e reflexões temporais, neste perpétuo esforço de reatualização do passado.

O que os grand-combianos vivem hoje é uma estrutura espaço-temporal que é todo este drama da reatualização do passado local em relação a vila outrora mineira: a identidade da vila compõe-se de fragmentos da descontinuidade de ser mineiro. Viver a vila, hoje, é um ato de arrumar, encadear e encaixar os diversos tempos e as diversas estruturas espaciais da história do grupo. Não querem mais ser uma vila mineira, mas reconstitui-la na memória. Querem permanecer, viver aí uma vila atual, moderna, e isto sem ter que obrigatoriamente lutar contra o passado. No espaço transfigurado, pedaços do passado tornam-se patrimônio cultural (maneira "moderna" de reatualizar o passado?); na monumentalidade, petrifica-se a memória do social. O que querem é que o trabalho de mineiro dure, mas se ele não pode continuar no interior da estrutura econômica atual, o savoir-faire torna-se ato de culto. Fixamse santuários (museus) onde possam reconstituir a família corporativa e render-lhe homenagem.

Os velhos ordenam suas referências identitárias a partir de sua relação atual com a vila. E isto diz respeito também aos jovens que são os herdeiros deste assalto de modernização aspirado por seus pais. Eles não se sentem, necessariamente, os "órfãos da mina", mas devem dar conta, simultaneamente, de viver um tempo de crise nesta vila e ser envelopados por referências identitárias mais globais.

Pela memória, os grand-combianos reencontram cotidianamente um senso para a vida. A memória tem este poder de reprodução do passado e de transformação do presente, um pouco espelho do passado, um pouco idealização de um devir coletivo. Esta reatualização dáse na representação de um outro ritmo cotidiano vivido. Ritmos temporais que lhes são 
dialeticamente estranhos e familiares, conflituais e desejados, que colocam em evidência afrontamentos de forças conservadoras e forças transformadoras, mas que colocam ainda em destaque esta força de combinar seus ritmos para construir um tempo que lhes assegure, numa temporalidade ondulatória (cíclica), a continuidade.

Assim, mesmo que uma nova cidade La Grand-Combe seja construída, ela o será sobre as ruínas da vila mineira. Ela é esta testemunha eterna lembrando que não importa o que venha ser o futuro construído pela vila, os homens ali estarão e, em alguma medida, terão sempre que dar conta que outrora, a vila fora mineira. Acabarão por ser obrigados a assumir um passado que não morre jamais, enquanto o futuro for construído por eles próprios. Porque se tudo muda, as pessoas não param de compor uma continuidade. Porque se a ruptura é morte, ela o é na dimensão de uma tragédia, e apesar da morte física, os homens não cessam de criar a vida. Porque enquanto a humanidade existir, não termina esta força de estabelecer um tempo humanitário que se solidarize com o esforço de construir uma "duração" social.(22)

\footnotetext{
22. "La communauté ne doit-elle pas constamment, pour exister, renouer avec son temps, retrouver sa durée?" In:
} ZONABEND. 1980. p. 17. 


\section{REFERÊNCIAS}

AREVEN, T. Family time and industrial time. N.Y., Cambridge University Press, 1982.

ARIES, P. Histoire des populations françaises. Paris, Seuil, 1971. 412 p.

ATTALI, J. Histoires du temps. Paris, Fayard, 1982. 333 p.

BACHELARD, G. La dialectique de la durée. Paris, Quadrige/PUF, 1989(a). 151 p. (1ed 1950).

BACHELARD, G. La poétique de l'espace. Paris, Quadrige/PUF, 1984. 215 p. (1ed 1957).

BALANDIER, G. Les anthropo-logiques dans la modernité. Paris, L.G.F., 1985(a). 320 p. (1ed 1974).

BALANDIER, G. Sens et puissance. Les dynamiques sociales. Paris, Quadrige/PUF, 1986. (1ed: 1971). 334 p.

BAUDRILLARD, J. La société de consommation. Paris, Denoël, 1970. 321 p.

BEAUVOIR, S. La vieillesse. Tome I et Tome II. Paris, Gallimard, 1970. 882 p.

BERGER, P. I. et LUCKMANN, T. A construç _ao social da realidade. 5 ed. Pétropolis, Vozes, 1983. $247 \mathrm{p}$.

BERGSON, H. Matéria e memória. S.P. Martins Fontes, 1990.

BOSI, E. Memória e sociedade. Lembranças de velhos. São Paulo, Queiroz ED. Ltda. e EDUSP, 1987.

BOTT, E. Família e rede social. Rio de Janeiro, Francisco Alves, 1976. 319 p. (1ed 1971).

BOURDIEU, P. "L'Identité et la représentation. Eléments pour une réflexion critique sur l'idée de région". In: Actes de la Recherche en Sciences Sociales. 1980. n 35. Paris, De Minuit. ps. 57 à 69.

BOURDIEU, P. Algérie 60. Structures économiques et structures temporelles. Paris, De Minuit, 1977. $125 \mathrm{p}$.

BOURDIEU, P. e SAYAD, A. Le Déracinement. Paris, Minuit, 1964. 226 p.

BOURDIEU, P. La distinction. Paris, De Minuit, 1979. 670 p.

BOURDIEU, P. Esquisse d'une théorie de la pratique. Genève-Paris, Droz, 1972. p. 178.

$\mathrm{BOZON}$, M. Vie quotidienne et rapports sociaux dans une petite ville de province: la mise en scène des différences. Lyon, P.U. de Lyon. 1984. 300 p.

BRANDAO, C.R. A cultura na rua. Campinas, Papirus, 1989. 219 p.

BRAUDEL, F. Ecrits sur l'histoire. Paris, Flammarion, 1969. 315 p.

BRAUDEL, F. L'Identité de la France. Espace et histoire. Paris, Arthaud-Flammarion, 1986.

$68 \mathrm{p}$.

CARDOSO DE OLIVEIRA, R. Identidade, etnia e estrutura social. S. P., Pioneira, 1976. $118 \mathrm{p}$.

CASTORIADIS, C. L'expérience du mouvement ouvrier. Tome I et II. Paris, U.G.E., 1974. $888 \mathrm{p}$.

CHOMBART DE LAUWE, P-H. La fin des villes. Mythe ou réalité. Paris, Calman-Lévy, 1982. 246 p.

DA MATTA, R. A Casa \& Rua. Espaço, cidadania, mulher e morte no Brasil. São Paulo, Brasiliense, $1985.140 \mathrm{p}$.

DEBOIS, E; JEANNEAU, Y; MATTEI, B. La foi des charbonniers. Les mineurs dans la bataille du charbon, 1945-1947. Paris, E.M.S.H, 1986. 194 p. 
DEVILLERS, C. e HUET, B. Le Creusot. Naissance et développement d'une ville industrielle, 1782-1914. Seyssel, E.C.V., 1981. 287 p.

DIAS DUARTE, L.F. Da vida nervosa, nas classes trabalhadoras urbanas. R.J., J. Zahar E./CNPq, 1986. 290 p.

DONZELOT, J. La police des familles. Paris, De Minuit, 1977. 221 p.

DUCKERT, J. e LARGUIER, C. La Grand-Combe: Evolution, Immobilité. Reconversion. M.M.G.A.L., L.S.H. Uv. Paul-Valéry, Montpellier III. 1987. 200 p.

DUMAZEDIER, J. Vers une civilisation du loisir? Paris, Seuil, 1982. 309 p. (1ed. 1962).

DUMONT, L. Essais sur l'individualisme. Paris, Seuil, 1983. 284 p.

DUMONT, L. Homo hierarchicus. Le système des castes et ses implications. Paris, Gallimard, 1966. 449 p.

DUVIGNAUD, J. Festas e Civilizações. EUF.Ceará e Tempo Brasileiro, 1983. p. 100.

DUVIGNAUD, J. La solidarité. Liens de sang et liens de raison. Paris, Fayard, 1986. 235 p.

ECO, U. La guerre du faux. Paris, Grasset \& Fasquelle, 1985. 377 p.

EWALD, F. L'Etat Providence. Paris, Grassets, 1986. 608 p.

FERRAROTTI, F. Histoire et histoires de vie. Paris, Librairie des Méridiens, 1983. 195 p.

FLANDRIN, J-L. Familles, parenté, maison, sexualité dans l'ancienne société. Paris, Seuil, 984. 288 p. (1ed: 1976).

FLECHON, E. Trente ans de fond. Manuscrit. (1927-1963). Châteaurenard, 1987. Tome I: 200 p.; Tome II: 300 p.

FORTIN, A. Histoires de familles et de réseaux. Montréal, Saint-Martin, 1987. 225 p.

FOUCAULT, M. Surveiller et punir. Paris, Gallimard, 1975. 318 p.

FREY, J-P. La ville industrielle et ses urbanités. Bruxelles, P.M. (A. R. n 25). 1986. 386 p.

GAILLARD, J-M. Un exemple français de "ville-usine": La Grand-Combe (Gard) et sa

"Compagnie des mines" (1836-1921). Thèse 3ème cycle. Nanterre, 1974. 330 p.

GEERTZ, C. A interpretação das culturas. R. J., Zahar, 1978. 321 p. (1ed 1973).

GOFFMAN, E. La mise en scène de la vie quotidienne. Paris, De Minuit, 1973. 251 p.

GOFFMAN, E. Les rites d'interaction. Paris, De Minuit, 1974. 231 p.

HALBWACHS, M. Mémoire collective. Paris, PUF, 1968. 204 p.

HALL, E. La danse de la vie. Temps culturel, temps vécu. Paris, Seuil, 1984. 283 p. (1ed 1983).

HOUTART, F. e LEMERCINIER, G.. De la perception de la durée à la construction du temps. Louvain, U.C.L: C.R.S-R, 1986.

JEUDY, H-P. Mémoires du social. Paris, PUF, 1986. 171 p.

KAUFMANN, J-C. La chaleur du foyer. Paris, Méridiens Klincksieck, 1988. 192 p. L'ECOLE DE CHICAGO. Naissance de l'écologie urbaine. Paris, Aubier Montaigne, 1984.

334 p. (1ed: 1979).

LAMORISSE, R. La population de la Cévenne Languedocienne. M.E.N., C.N.R.S., U. PaulValéry, Montpellier, 1975.

LE GOFF, J. Histoire et mémoire. Paris, Gallimard, 1988. 409 p. (1ed: 1977).

LE GOFF, J. Le Pays Cévenol et Cévennes. Hebdomadaire régional. Dép. Gard. Anos: 1982 à 1983, 1988 à 1991.

LE GOFF, J. Le Petit Cévenol. Hebdomadaire régional. Dép. Gard. Anos: 1988 à 1990.

LEFEBVRE, H. Le droit à la ville suivi de Espace et politique. Paris, Ed. Anthropos, 1968 et 1972. $281 \mathrm{p}$. 
LEITE LOPES, J.S. O vapor do diabo. R. J., Paz e Terra, 1978. 220 p. (led. 1976).

LEITE LOPES, J.S. (Org). Cultura \& Identidade Operária. RJ, Marco Zero, 1987. 226 p.

LEROI-GOURHAN, A. "Memória e ritmos". In: O gesto e a palavra. Tomo 2. Lisboa, Ed. 70, 1985. 246 p. (1ed. 1965).

LEVI-STRAUSS, C. "L'Identité". (Actes Séminaire dirigé par) Paris, Quadrige/PUF, 1983. 335 p. (1ed 1977).

LEVI-STRAUSS, C. As estruturas elementares do parentesco. Petrópolis, Vozes, 1976. 537 p. (1ed: 1949).

LIVET, G. La Grand'Combe à travers les âges. Alès, Imp. Compan-Brabo, 1956. 39 p.

LUCAS, P. La religion de la vie quotidienne. Paris, PUF, 1981. 140 p.

LUCAS, P. La rumeur minière ou le travail retravaillé. Paris, P.U. de Lyon, 1985. 168 p.

MACHADO DA SILVA, L.A. (org.). Condiç _oes de vida das camadas populares. Rio de Janeiro, Zahar, 1984. p. 21 à 58.

MAUSS, M. Manuel d'ethnographie. Paris, Payot, 1967. 262 p. (1ed 1947).

MAUSS, M. Sociologie et anthropologie. Paris, Quadrige/PUF, 1985. 482 p. (1ed 1950).

MICHEL, A. Sociologie de la famille et du mariage. Paris, PUF, 1986. 263 p. (1ed. 1972).

MICHEL, A. Midi Libre. Grand Quotidien d'Information du Midi. Alès et Cévennes. Années: 1988 à 1990.

MURARD, L e ZYLBERMAN, P. Le petit travailleur infatigable ou le prolétaire régénéré. Paris, CERFS., 1976. 292 p.

NAMER, G. Mémoire et société. Paris, Méridiens Klincksieck, 1987. 242 p.

NOIRIEL, G. Le Creuset Français. Histoire de l'immigration XIXe-XXe siècles. Paris, Seuil, 1988. $441 \mathrm{p}$.

NOIRIEL, G. Les ouvriers dans la société française XIXe-XXe Siècle. Paris, Seuil, 1986. 321

p.

NOSCHIS, K. Signification affective du quartier. Paris, Librairie des Méridiens, 1984. 170 p. PACZKOWSKI, C. e VIELZEUF, A. La Grand'Combe en Cévenne, jadis canton de gueules noires. Nîmes, C. L.E., 1989. 206 p.

PAUL-LEVY, F. e SEGAUD, M. Anthropologie de l'espace. Paris, C.C.I/C.G.P., 1983.346p. PELEN, J-N. L'autrefois des cévenols. Aix-en-Provence, Edisud, 1987. 192 p.

PINÇON, M. Désarrois ouvriers. Paris, L'Harmattan, 1987. 184 p.

PITT-RIVERS, J. Anthropologie de l'honneur. Paris, Le Sycomore, 1983. 275 p. (led. 1977).

PUECH. La Compagnie de la Grand-Combe. Société Anonyme - Capital 6.375.OOO. Paris, E.N.M., 1901. Tome I: 363 p. Tome II: 558 p. Manuscrit.

PUECH. Recensements de la Population. Commune de La Grand-Combe de 1846 à 1990.

Mairie de La Grand-Combe.

PUECH. Règlements Mines de Grand'Combe: a) Caisse de Secours, 1854. b) Société de Prévoyance, 1891. c) Sécurité Sociale Minière, 1920.

REVUE SOCIETES. "Temps libre - Dumazedier". Revue des SHS. Paris, Dunod, 1991, n 32.

RICOEUR, P. et alii. As culturas e o tempo. Petrópolis, São Paulo, Vozes e EUSP, 1975.283p.

SAHLINS, M. Cultura e razão prática. Rio de Janeiro, Zahar, 1979. 258 p. (1ed 1976).

SAMUEL, N. Le temps libre: temps social. Paris, Méridien Klincksieck. 
SCHWARTZ, O. Le monde privé des ouvriers. Hommes et femmes du Nord. Paris, PUF 1990. 544 p.

SEGALEN, M (direction). L'autre et le semblable. Paris, Presses du CNRS, 1989. 240 p.

SEGALEN, M. Sociologie de la famille. Paris, Armand Colin, 1981. 335 p.

SENNETT, R. Autorité. Paris, Fayard, 1981. 286 p.

SENNETT, R. Statuts: a) Société Grand'combienne d'Alimentation. 1920. b) Société de Secours Mutuels des Ouvriers et Employés des Mines de la Grand'Combe. 1920.

TEIXEIRA, S.A; ORO, A.P. (Org.) Brasil\&França. Ensaios de Antropologia Social. Porto Alegre, E. da UFRGS, 1992. 167 p.

TOURAINE, A. e DUBET, F e et alii. Le pays contre l'Etat. Luttes occitanes. Paris, Seuil, 1981. $188 \mathrm{p}$.

TREMPE, R. Les mineurs de Carmaux 1848-1914. Paris, Les Editions Ouvrières, 1971. Tome I et II. $1012 \mathrm{p}$.

TREMPE, R. Les trois batailles du charbon. 1936-1947. Paris, La Découverte, 1989. 256 p. TURNER, V. O processo ritual. Estrutura e antiestrutura. Petrópolis, Vozes, 1974. 245 p. (1ed. 1969).

WEIL, S. L'enracinement. Paris, Gallimard, 1949. 380 p.

WIENIN, M. Le pays d'Alès. Alès, Saber, 1986. 86 p.

YOUNG, M. e WILLMOTT, P. Le village dans la ville. Paris, C.G.P/CCI, 1983. 255 p. (1ed. 1957).

ZOLA, E. Germinal. Paris, Folio, 1978. (1ed. 1885).

ZONABEND, F. La mémoire longue. Temps et histoires au village. Paris, PUF, 1980. 314 p. 